\title{
FUT family mediates the multidrug resistance of human hepatocellular carcinoma via the PI3K/Akt signaling pathway
}

\author{
L Cheng ${ }^{1,2}$, S Luo ${ }^{3}$, C Jin ${ }^{4}, \mathrm{H} \mathrm{Ma}^{1}$, H Zhou ${ }^{5}$ and L Jia ${ }^{*, 1}$
}

The fucosyltransferase (FUT) family is the key enzymes in cell-surface antigen synthesis during various biological processes such as tumor multidrug resistance (MDR). The aim of this work was to analyze the alteration of FUTs involved in MDR in human hepatocellular carcinoma (HCC) cell lines. Using mass spectrometry (MS) analysis, the composition profiling of fucosylated $\mathrm{N}$-glycans differed between drug-resistant BEL7402/5-FU (BEL/FU) cells and the sensitive line BEL7402. Further analysis of the expressional profiles of the FUT family in three pairs of parental and chemoresistant human HCC cell lines showed that FUT4, FUT6 and FUT8 were predominant expressed in MDR cell lines. The altered levels of FUT4, FUT6 and FUT8 were responsible for changed drug-resistant phenotypes of BEL7402 and BEL/FU cells both in vitro and in vivo. In addition, regulating FUT4, FUT6 or FUT8 expression markedly modulated the activity of the phosphoinositide 3 kinase (PI3K)/Akt signaling pathway and MDRrelated protein 1 (MRP1) expression. Inhibition of the PI3K/Akt pathway by its specific inhibitor wortmannin, or by Akt small interfering RNA (siRNA), resulted in decreased MDR of BEL/FU cells, partly through the downregulation of MRP1. Taken together, our results suggest that FUT4-, FUT6- or FUT8-mediated MDR in human HCC is associated with the activation of the PI3K/Akt pathway and the expression of MRP1, but not of P-gp, indicating a possible novel mechanism by which the FUT family regulates MDR in human HCC.

Cell Death and Disease (2013) 4, e923; doi:10.1038/cddis.2013.450; published online 14 November 2013

Subject Category: Cancer

Multidrug resistance (MDR) frequently contributes to the failure of chemotherapeutic drug treatments in patients diagnosed with cancer such as hepatic carcinoma. ${ }^{1}$ The mechanisms underlying the MDR of cancer cells are complex, ${ }^{2,3}$ including increase in drug efflux, reduction in drug absorption, changes in the targets of anticancer drugs, decrease in drug activity, enhancement of DNA repair following damage, changes in signaling pathway and so on. Classic MDR is the consequence of overexpression of transporter proteins belonging to the ATP-binding cassette $(A B C)$ family such as P-glycoprotein (P-gp) and MDR-related protein (MRP). Their function is to extrude antitumor agents from the cytoplasm, thus reducing intracellular drug concentrations to sublethal levels. ${ }^{4}$ Furthermore, the epithelialto-mesenchymal transition (EMT) is also associated with 5-fluorouracil (5-FU) resistance in hepatocellular carcinoma (HCC). ${ }^{5}$ The EMT is initiated and regulated by many different cytokines and growth factors during tumor progression.
Emerging evidence suggests that HCC cells, which have undergone the EMT, are responsible for resistance to chemotherapy. ${ }^{6}$ Recently, researchers pay more attention to the relationship between glycan alteration and resistance to chemotherapy of malignant cells. The changes of glycans on cell glycoproteins have been identified to be linked to drug resistance in $\mathrm{HCC}^{7,8}$ Although the alteration of glycan structure is observed in drug-resistance HCC cell line, little information is available about the reversal effects of glycosyltransferases and corresponding glycogenes on multidrug resistance in human HCC cells.

Glycan biosynthesis involves multiple glycosyltransferases in a complex multistep process that builds up carbohydrate structures on proteins and lipids. Each glycosyltransferase is specific for the acceptor structure, the transferred monosaccharide and the position the linkage it creates. ${ }^{9}$ The Fucosyltransferase (FUT) family is a group of fucosylation synthases. By catalyzing the transfer of fucose (Fuc) residue

\footnotetext{
${ }^{1}$ College of Laboratory Medicine, Dalian Medical University, Dalian, Liaoning Province, China; ${ }^{2}$ Department of Laparoscopic Surgery, The First Affiliated Hospital of Dalian Medical University, Dalian, Liaoning Province, China; ${ }^{3}$ Department of Traumatology, Shanghai Ruijin Hospital, Jiaotong University, Shanghai, China; ${ }^{4}$ Department of State-owned Property Management, Dalian Medical University, Dalian, Liaoning Province, China and ${ }^{5}$ Department of Microbiology, Dalian Medical University, Dalian, Liaoning Province, China

*Corresponding author: L Jia, College of Laboratory Medicine, Dalian Medical University, 9 Lvshunnan Road Xiduan, Dalian 116044, Liaoning Province, China. Tel: +86 411 86110386; Fax: +86 411 86110392; E-mail: jiali@ dlmedu.edu.cn

Keywords: FUT family; multidrug resistance; human hepatocellular carcinoma cell line; PI3K/Akt signaling; P-glycoprotein; MRP1

Abbreviations: FUT, fucosyltransferase gene; MDR, multidrug resistance; MS, mass spectrometry; 5-FU, 5-Fluorouracil; BEL/FU, BEL7402/5-FU; HepG2/FU, HepG2/ 5-FU; MHCC97H/FU, MHCC97H/5-FU; PI3K, phosphoinositide 3 kinase; MRP1, multidrug resistance-related protein 1; siRNA, small interfering RNA; P-gp, P-glycoprotein; HCC, hepatocellular carcinoma; PBST, PBS containing 0.1\% Tween 20; phosphate-buffered saline; MTX, methotrexate; VCR, vincristine; ADR, adriamycin; DMSO, dimethyl sulfoxide; MTT, methylthiazolyl tetrazolium; EMSA, electrophoretic mobility shift assay; IHC, immunohistochemical; EMT, epithelialto-mesenchymal transition

Received 24.6.13; revised 09.9.13; accepted 10.9.13; Edited by A Stephanou
} 
from the donor substrate, GDP-Fuc, to the oligosaccharide acceptor in $\alpha 1,2$-(FUT1 and FUT2), $\alpha 1,3 / 4-($ FUT3, FUT4, FUT5, FUT6, FUT7, FUT9, FUT10 and FUT11) and $\alpha 1$, 6-linkage (FUT8), FUTs promote the synthesis of fucosylated oligosaccharide chain of glycoconjugates. ${ }^{10-12}$ Fucosylated oligosaccharides have been implicated in multiple cell-cell interactions in differentiation, development and malignancy. ${ }^{13,14}$ Forced FUT1 and FUT2 expression in human ovarian carcinoma-derived RMG-I cells promoted cell proliferation and resistance against anticancer drugs, such as 5-FU and carboplatin. ${ }^{15,16}$ While increasing FUT4 and FUT7 expression promoted neoplastic cell proliferation and HCC cell growth in vitro, respectively, reducing FUT3/6 expression suppressed colon carcinoma cell proliferation. ${ }^{17-19}$ FUT6 was highly expressed in $\mathrm{HCC}$ and was positively associated with the progression of tumor. ${ }^{20,21}$ FUT7 modified the susceptibility of apoptosis in human hepatocarcinoma cells. ${ }^{22}$ FUT8 was also upregulated in human hepatoma cell line HCCLM3 (high metastasis). ${ }^{23}$ However, the effects of the FUT family on MDR have not yet been clearly defined in human HCC cells.

Activation of the phosphoinositide 3 kinase (PI3K)/Akt pathway has a pivotal role in essential cellular functions such as survival, proliferation, migration and differentiation that underlie the biology of human cancer. ${ }^{24,25}$ In addition, several reports highlight that aberrant activation of the PI3K/Akt pathway contributes to the drug resistance of different types of human cancer cells. Activation of Akt was associated with poor prognosis and chemotherapeutic resistance in pediatric B-precursor acute lymphoblastic leukemia. ${ }^{26}$ The PI3k/Akt pathway was involved in P-gp-associated survivin transcription activity in the multidrug-resistant MCF-7 breast cancer cells. ${ }^{27}$ Inhibition of the PI3K/Akt pathway or Akt small interfering RNA (siRNA) led to the inhibition of cellular prion protein $(\operatorname{PrP}(C))$-induced drug resistance in gastric cancer cells. ${ }^{28}$ However, little is known regarding the signaling pathways on FUT family-mediated HCC MDR.

Therefore, the aim of the present study was to determine fucosylated oligosaccharide alteration and differentially expressed FUT genes between the parental and chemoresistant human HCC cell lines by using mass spectrometry (MS) and real-time PCR. In addition, we wanted to investigate whether the FUT family participates in the regulation of tumor MDR via the PI3K/Akt pathway and the possible mechanisms. Our results provide further evidence that the differentially expressed FUT genes were possibly related to the MDR potential of human HCC cells.

\section{Results}

MALDI-MS analysis of $\mathrm{N}$-glycan composition profiling from BEL7402 and BEL/FU cells. MALDI-TOF MS analysis was utilized to evaluate the $\mathrm{N}$-glycan composition profiling of BEL7402 and BEL/FU cell lines. Figure 1 showed the MS spectra of $\mathrm{N}$-glycans released from cell membranes and the observed MS signals of the $\mathrm{N}$-glycans (peaks 1-33 in Figure 1a) and the assigned $\mathrm{N}$-glycan signals as were summarized in Table 1. The observed signal intensities in the mass spectra were presented as a histogram (Figure 1b),
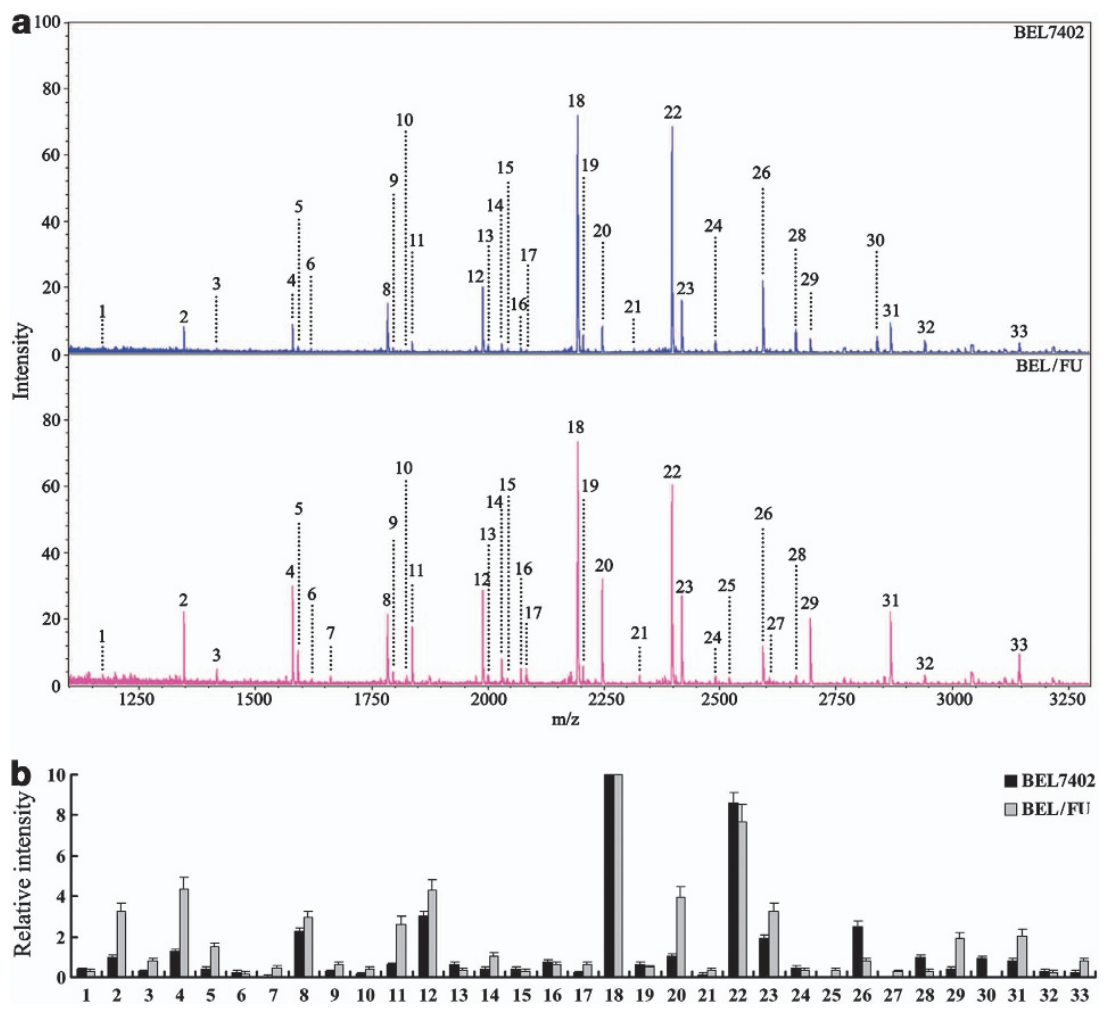

Figure 1 Differential N-glycan composition of BEL7402 and BEL/FU cell lines. (a) MALDI-TOF MS spectra of permethylated N-glycans released from BEL7402 and BEL/FU cells, respectively. (b) Histograms of relative intensities of the differential glycan signals were observed. Data were analyzed as described in Materials and Methods and are the average \pm S.D. of triplicate determinations. The signals indicated with Arabic numerals are summarized in Table 1 
with the estimated monosaccharide composition. Highmannose glycans (peaks 4, 8, 12, 18 and 22) were observed in both cell lines (Table 1). The N-glycans detected in BEL/FU cells showed remarkably different profiles versus those of BEL7402 cells. The peaks at $7,25,27$ were exclusively detected only in the drug-resistant BEL/FU cell line. Peak 30 was detected exclusively in the BEL7402 cell line. BEL/FU cells showed higher incidence of additional significant peaks at 2, 3, 4, 5, 11, 20, 29, 31 and 33. Peaks 26, 28, 29 clearly showed a significant increase in the BEL7402 cell line. Surprisingly, the most significant increase peaks corresponding to fucosylated oligosaccharides were observed at peaks 2, 5, 11, 20, 27, 29 and 31 in BEL/FU cells. The fucosylated oligosaccharides observed at peaks 26 and 28 also showed significant increase in the BEL7402 sample. These data indicated that differential $\mathrm{N}$-glycan composition profiling might be associated with the development of MDR in human $\mathrm{HCC}$, especially fucosylated oligosaccharides.

Differential expression of the FUT gene family in three pairs of parental and chemoresistant human HCC cell lines. The MALDI-TOF MS profiles of $\mathrm{N}$-glycan composition from BEL7402 and BEL/FU also showed different fucosylation levels between the drug-sensitive BEL7402 and the MDR BEL/FU cells and a higher level of fucosylated oligosaccharides in BEL/FU cells (Figure 1 and Table 1). In order to evaluate further the expression profile of FUT genes in the parental and chemoresistant human HCC cell lines, a real-time RT-PCR analysis was performed. As shown in Figure 2a, no statistically significant differences were found in the expression of FUT1, FUT2, FUT5, FUT7 and FUT11 mRNA. Only slight differences were observed in the levels of FUT3 (1.7-folds), FUT9 (1.5-folds) and FUT10 (1.8-folds) mRNA. Comparing with BEL7402 cells, BEL/FU cells showed a remarkable expression of FUT4 (3.5-folds), FUT6 (3.0-folds) and FUT8 (3.8-folds) mRNA, suggesting that BEL/FU cells displayed higher $\alpha 1,3-$ and $\alpha 1,6$-linked fucosylation (core fucosylation). In addition, HepG2/FU and $\mathrm{MHCC} 97 \mathrm{H} / \mathrm{FU}$ cells showed the same tendency. These data indicated that differential FUT gene expression might be associated with MDR of human HCC cell lines.

Silence of FUT4, FUT6 or FUT8 genes enhances the chemosensitivity of BEL/FU cells both in vitro and in vivo. Owing to the significant increase in FUT4, FUT6 or FUT8 mRNA expression in BEL/FU cells (Figure 2a), we silenced, by shRNA, FUT4, FUT6 or FUT8 in order to elucidate the direct implication FUT4, FUT6 or FUT8 in the chemosensitivity of BEL/FU cells. As shown in Figures $3 a$ and $b$, the expression level of FUT4, FUT6 or FUT8 was

Table $1 \mathrm{~N}$-glycans analyzed in BEL7402 and BEL7402/5-FU cell lines by MALDI-TOF MS

\begin{tabular}{|c|c|c|c|c|c|c|c|c|}
\hline \multirow[t]{2}{*}{ Peak no. } & \multicolumn{2}{|c|}{ Observed $m / z$} & \multicolumn{6}{|c|}{ Composition } \\
\hline & BEL7402 & BEL7402/5-FU & Hex & HexNAc & Man & GIcNAc & NeuAc & Deoxyhexose \\
\hline 1 & 1171.87 & 1171.89 & 0 & 0 & 3 & 2 & 0 & 0 \\
\hline 2 & 1345.95 & 1345.92 & 0 & 0 & 3 & 2 & 0 & 1 \\
\hline 3 & 1417.06 & 1416.99 & 0 & 1 & 3 & 2 & 0 & 0 \\
\hline 4 & 1580.13 & 1580.09 & 0 & 0 & 5 & 2 & 0 & 0 \\
\hline 5 & 1591.08 & 1591.10 & 0 & 1 & 3 & 2 & 0 & 1 \\
\hline 6 & 1621.40 & 1621.07 & 1 & 1 & 3 & 2 & 0 & 0 \\
\hline 7 & No & 1662.06 & 0 & 2 & 3 & 2 & 0 & 0 \\
\hline 8 & 1784.25 & 1784.22 & 0 & 0 & 6 & 2 & 0 & 0 \\
\hline 9 & 1795.28 & 1795.22 & 1 & 1 & 3 & 2 & 0 & 1 \\
\hline 10 & 1825.34 & 1825.20 & 2 & 1 & 3 & 2 & 0 & 0 \\
\hline 11 & 1836.34 & 1836.24 & 0 & 2 & 3 & 2 & 0 & 1 \\
\hline 12 & 1988.31 & 1988.28 & 0 & 0 & 7 & 2 & 0 & 0 \\
\hline 13 & 1999.33 & 1999.24 & 2 & 1 & 3 & 2 & 0 & 1 \\
\hline 14 & 2029.27 & 2029.29 & 3 & 1 & 3 & 2 & 0 & 0 \\
\hline 15 & 2040.16 & 2040.35 & 1 & 2 & 3 & 2 & 0 & 1 \\
\hline 16 & 2070.41 & 2070.29 & 2 & 2 & 3 & 2 & 0 & 0 \\
\hline 17 & 2081.56 & 2081.32 & 0 & 3 & 3 & 2 & 0 & 1 \\
\hline 18 & 2192.31 & 2192.29 & 0 & 0 & 8 & 2 & 0 & 0 \\
\hline 19 & 2203.35 & 2203.30 & 3 & 1 & 3 & 2 & 0 & 1 \\
\hline 20 & 2244.34 & 2244.29 & 2 & 2 & 3 & 2 & 0 & 1 \\
\hline 21 & 2326.34 & 2326.35 & 0 & 4 & 3 & 2 & 0 & 1 \\
\hline 22 & 2396.28 & 2396.27 & 0 & 0 & 9 & 2 & 0 & 0 \\
\hline 23 & 2418.31 & 2418.27 & 2 & 2 & 3 & 2 & 0 & 2 \\
\hline 24 & 2489.25 & 2489.29 & 2 & 3 & 3 & 2 & 0 & 1 \\
\hline 25 & No & 2519.18 & 3 & 3 & 3 & 2 & 0 & 0 \\
\hline 26 & 2592.23 & 2592.20 & 2 & 2 & 3 & 2 & 0 & 3 \\
\hline 27 & No & 2605.17 & 2 & 2 & 3 & 2 & 1 & 1 \\
\hline 28 & 2663.20 & 2663.18 & 2 & 3 & 3 & 2 & 0 & 2 \\
\hline 29 & 2693.22 & 2693.16 & 3 & 3 & 3 & 2 & 0 & 1 \\
\hline 30 & 2839.00 & No & 4 & 2 & 3 & 2 & 1 & 0 \\
\hline 31 & 2867.08 & 2867.06 & 3 & 3 & 3 & 2 & 0 & 2 \\
\hline 32 & 2938.00 & 2938.15 & 3 & 4 & 3 & 2 & 0 & 1 \\
\hline 33 & 3141.84 & 3141.86 & 4 & 4 & 3 & 2 & 0 & 1 \\
\hline
\end{tabular}

Abbreviations: GlcNAc, N-acetylglucosamine; Hex, hexose; HexNAc, N-acetylhexosamine; Man, mannose; NeuAc, N-acetylneuraminic acid The N-glycans were observed as $[\mathrm{M}+\mathrm{Na}]+$ 
significantly reduced in BEL/FUT-shRNA transfectants compared with control transfectants. Furthermore, the $\alpha-1,3$ fucosylation level detected by FITC-LTL lectin on the cell surface was reduced in BEL/FU-FUT4 shRNA and FUT6 shRNA cell lines (Figure 3c). Fluorescence intensity on FITCLCA also revealed less $\alpha-1,6$ fucosylation in FUT8 shRNA cells than that in nontransfection cells (Figure $3 c$ ). These results clearly showed that FUT4, FUT6 or FUT8 was responsible for the overcoming tumor cells' MDR via regulating fucosylation profile in terms of $\alpha-1,3$ or $\alpha-1,6$ branched structures in HCC cells.

After FUT4, FUT6 or FUT8 shRNA transfection, the ability of 5-5-FU, methotrexate (MTX), vincristine (VCR) and
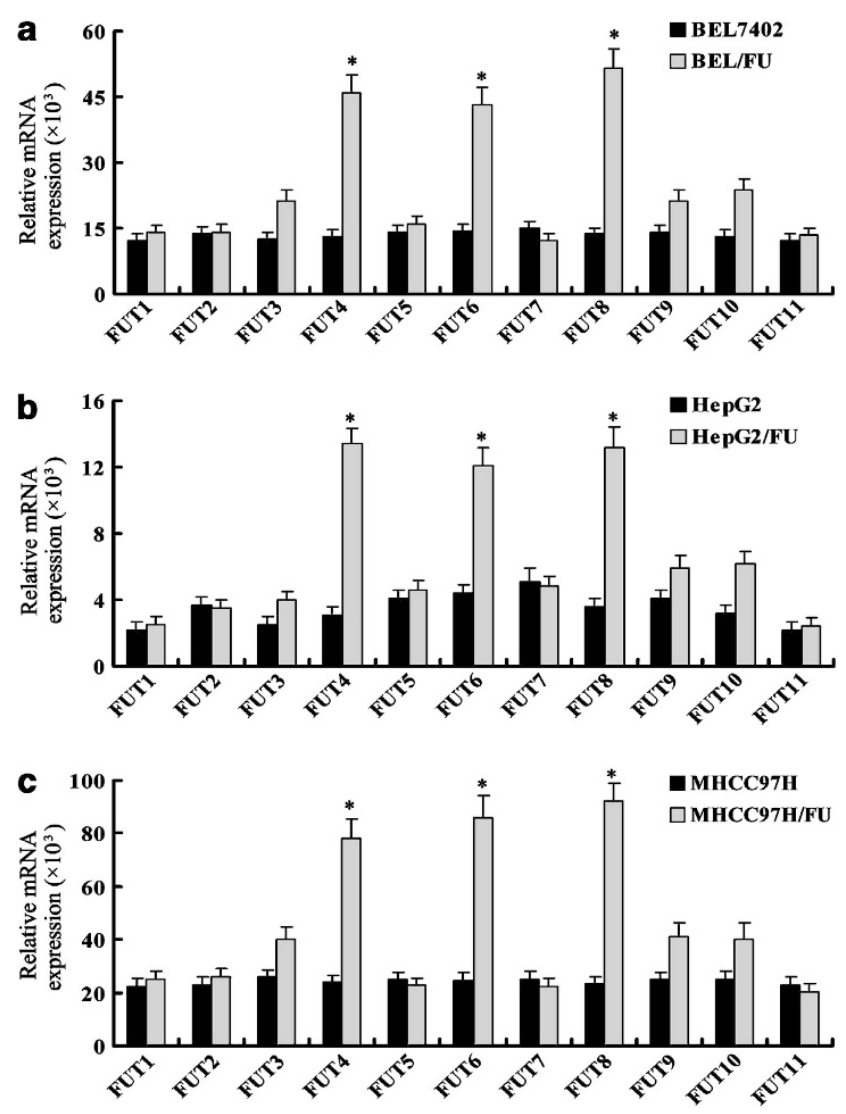

Figure 2 Differential expression of the FUT gene family in three pairs of parental and chemoresistant human hepatocellular carcinoma cell lines. (a-c) The mRNA levels of FUT gene family analyzed using real-time RT-PCR. The relative amount of gene mRNA level was normalized to the GAPDH level. Three MDR cells expressed higher levels of FUT4, FUT6 and FUT8 mRNA than their parental cell types (more than threefold; ${ }^{*} P<0.05$ ). Data are the means \pm S.D. of triplicate determinants adriamycin (ADR) to inhibit the growth of BEL/FUT cells was evaluated using MTT assay. The results showed that $\mathrm{IC}_{50}$ values (drug concentration that inhibits cell growth by $50 \%$ ) were significantly decreased in BEL/FU-FUT4 shRNA cells group compared with the control, suggesting that cell proliferation was inhibited by therapeutic drug when BEL/FU cells were treated with FUT4 shRNA. Similar results were obtained with BEL/FU-FUT6 or FUT8 shRNA cell group, chemosensitivity was remarkably restored when the FUT6 or FUT8 gene was suppressed (Figure 3d). In addition, MTS assay also revealed the same tendency (Supplementary Figure 1a).

To investigate the effect of knockdown of the FUT4, FUT6 or FUT8 gene on cell chemosensitivity in vivo, we used nude mice bearing BEL/FU, BEL/FU-FUT4 shRNA, BEL/FU-FUT6 shRNA and BEL/FU-FUT8 shRNA xenografts to analyze the differences of tumor volumes when therapeutic drugs were administrated. Figure $3 e$ showed that a significant reduction in the mean tumor volume of BEL/FU-FUT4 shRNA tumor $\left(411 \pm 72 \mathrm{~mm}^{3}\right)$ was observed, as compared with the control shRNA group $\left(803 \pm 119 \mathrm{~mm}^{3}\right)$, and the effect of concomitant application of 5-FU. The same tendency was also seen in BEL/FU-FUT6 shRNA $\left(405 \pm 69 \mathrm{~mm}^{3}\right)$ and FUT8 shRNA groups $\left(420 \pm 65 \mathrm{~mm}^{3}\right)$. In the FUT4 pretreatment BEL/FU xenograft model, the percent reduction in tumor volume in the presence and absence of 5-FU upon control shRNA versus FUT4 shRNA were $48.82 \%$ and $38.22 \%$, respectively. Similar results were obtained in the FUT6 (49.56\%, 39.92\%) or FUT8 (47.69\%, 39.12\%) pretreatment BEL/FU xenograft model. These data were consistent with the results of in vitro chemosensitivity analysis.

After the measurements of the tumor volumes, tumors were sectioned for real-time PCR and IHC (immunohistochemical) staining analysis of FUT4, FUT6 and FUT8 expression patterns; these three genes and proteins were reduced in the mice group with shRNA treatment compared with the untreated group or control group (Figures $3 f$ and $g$ ), suggesting a positive correlation between the three gene expression and chemoresistance of BEL/FU cells. Further IHC assessment of the nuclear antigen Ki67 was used to estimate cell proliferation. The results demonstrated that the expression level of Ki67 was significantly decreased in xenograft tumor originating from FUT4-, FUT6- or FUT8depleted cells, compared with control cells (Supplementary Figure 2a).

Overexpression of the FUT4, FUT6 or FUT8 gene enhances the chemoresistance of BEL7402 cells both in vitro and in vivo. After verifying the effect of FUT4, FUT6 and FUT8 gene suppression on tumor cell chemosensitivity,

Figure 3 Silence of FUT4, FUT6 or FUT8 gene enhances the chemosensitivity of BEL/FU cells both in vitro and in vivo. (a) Silencing of FUT4, FUT6 or FUT8 in BEL/FU cells was analyzed with the RNAi approach. FUT4, FUT6 or FUT8 transcript was decreased apparently in BEL/FU cells by shRNA treatment. (b) After shRNA transfection, distinct reduction in FUT4, FUT6 or FUT8 was observed at protein levels using western blot analysis. (c) FITC-LTL- or FITC-LCA-binding profile of FUT4, FUT6 or FUT8 shRNA cells using flow cytometry. Histograms of fluorescence intensities of cells with specific carbohydrate expression as determined. (d) Cell chemosensitivity was assessed using cytotoxicity assays. The reported values were the $I_{50}$ (Mean \pm S.D.) of three independent experiments. $I_{50}$ represents the drug concentration producing $50 \%$ decrease in cell growth. ${ }^{*} P<0.05$ versus BEL/FU-control shRNA cells. (e) A decrease in the mean tumor volume in mice group with BEL/FU-FUT4, FUT6 or FUT8 shRNA tumors was observed, as compared with that in the BEL/FU group and the BEL/FU-control shRNA group. Within the BEL/FU-FUT4, FUT6 or FUT8 shRNA group, an increase in tumor growth was found in group without 5-FU, compared with that with 5-FU $\left({ }^{*} P<0.05\right)$. Downregulation of FUT4, FUT6 or FUT8 was also shown using real-time RT-PCR $(\mathbf{f})$ and IHC staining $(\mathbf{g})$ in xenograft tumors derived from BEL/FU-FUT4 shRNA, BEL/FU-FUT6 shRNA or BEL/FU-FUT8 shRNA cells $(400 \times)$. The data are means \pm S.D. of three independent assays $\left({ }^{\star} P<0.05\right)$ 
we next transfected BEL7402 cells with FUT4, FUT6 or FUT8 expression vector to determine the effect of overexpression of these genes on chemoresistance of BEL7402 cells. Notably, increased levels of mRNA and protein of
FUT4, FUT6 and FUT8 were detected in BEL7402 transfectants (Figures $4 \mathrm{a}$ and $\mathrm{b}$ ). Figure $4 \mathrm{c}$ also showed that the FUT4, FUT6 or FUT8 overexpression resulted in an increase in fluorescence intensity $(\alpha-1,3$ or $\alpha-1,6$ fucosylation) a
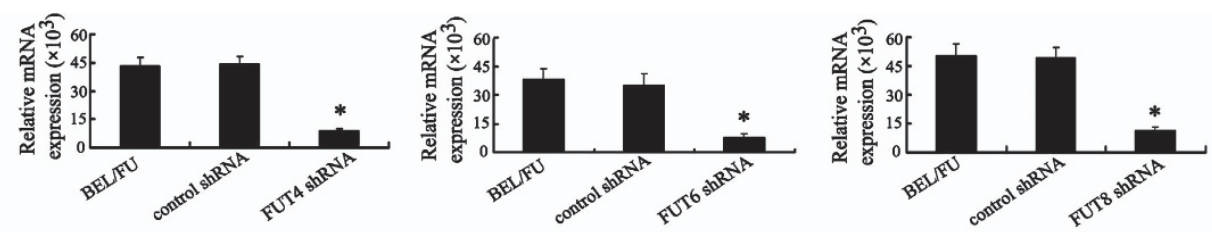

b

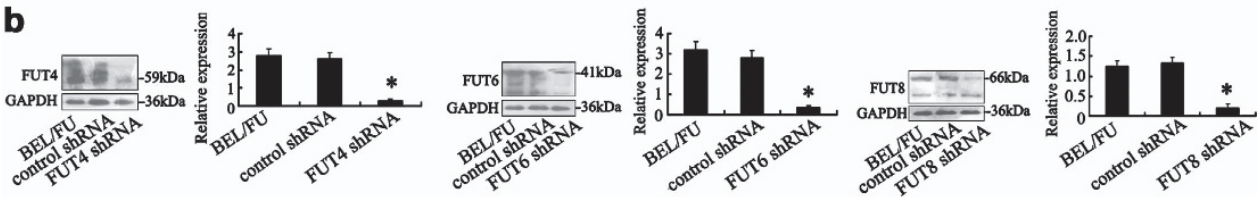

C
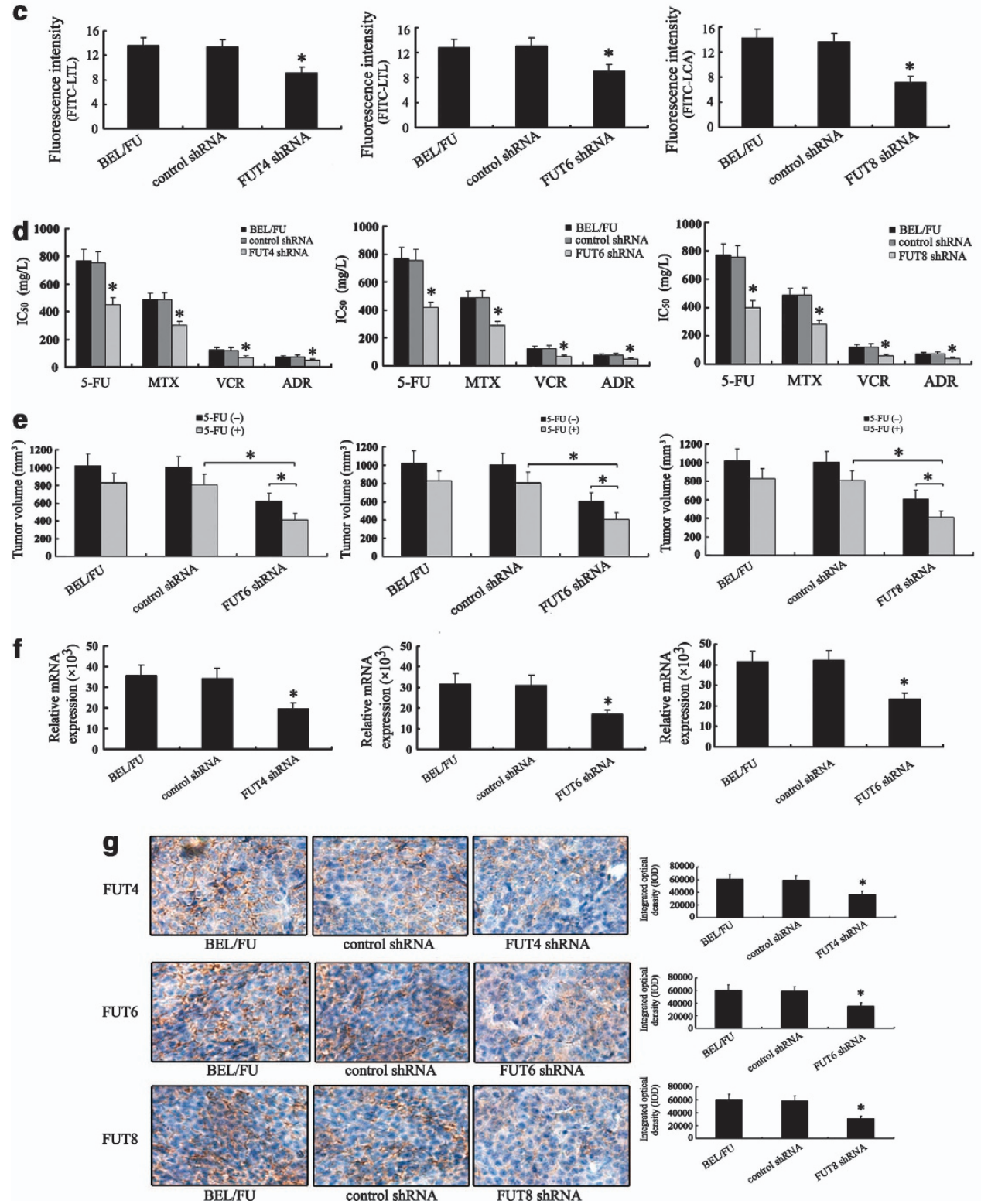
a
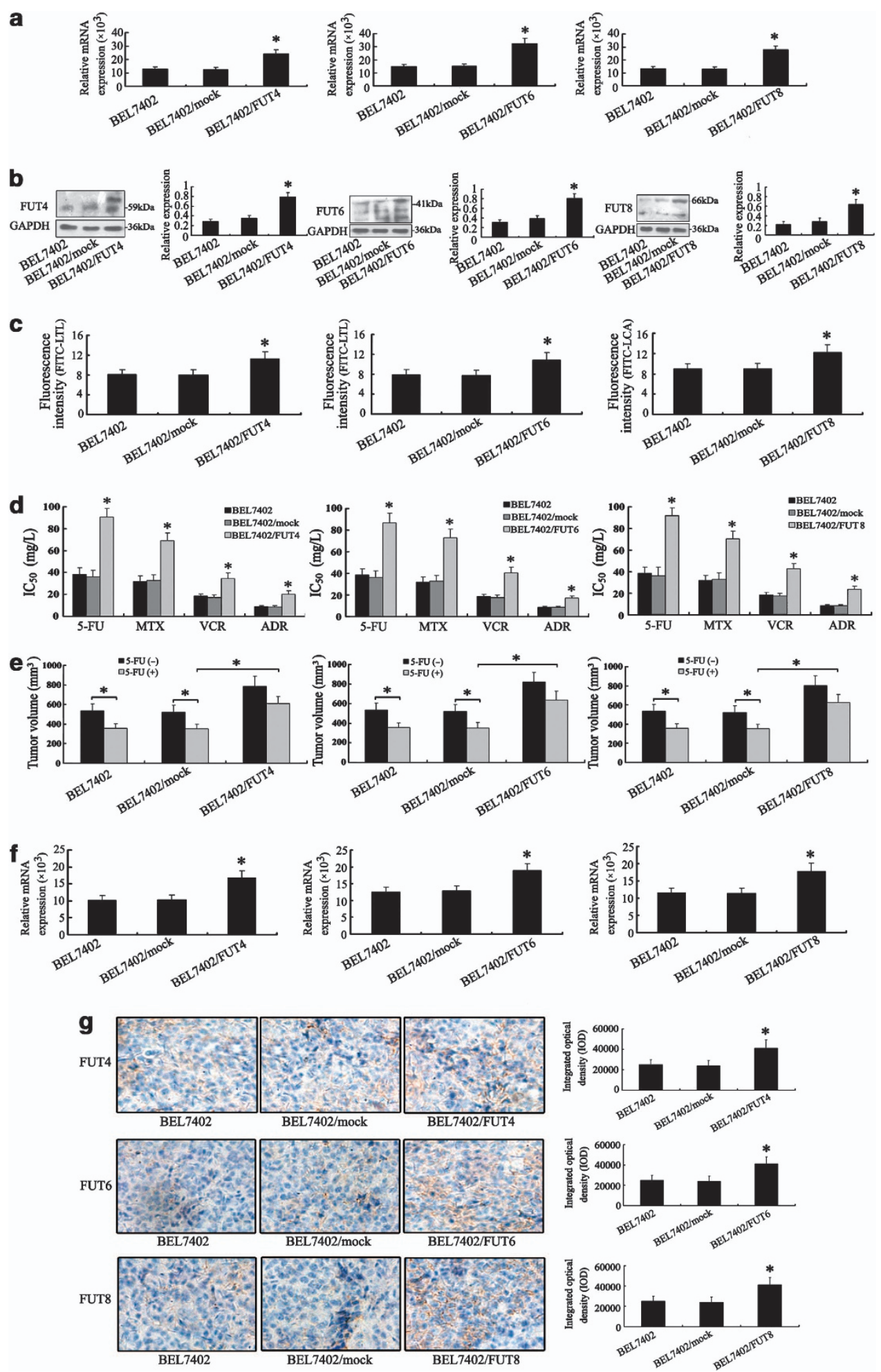

Figure 4 Overexpression of FUT4, FUT6 or FUT8 gene enhances the chemoresistance of BEL7402 cells both in vitro and in vivo. After full-length sequence transfection, FUT4, FUT6 or FUT8 mRNA (a) and protein (b) were increased notably in BEL7402 cells using real-time PCR and western blot. (c) FITC-LTL-or FITC-LCA-binding profile of BEL7402/FUT4, BEL7402/FUT6 or BEL7402/FUT8 cells using flow cytometry. Histograms of fluorescence intensities of cells with specific carbohydrate expression as determined. (d) Cell chemosensitivity was assessed using cytotoxicity assays. The reported values were the $I_{50}$ (Mean \pm S.D.) of three independent experiments. $\mathrm{IC}_{50}$ represents the drug concentration producing $50 \%$ decrease in cell growth. ${ }^{*} P<0.05$ versus $\mathrm{BEL} 7402 / \mathrm{mock}$ cells. (e) An increase in the mean tumor in the mice group with BEL7402/FUT4, BEL7402/FUT6 or BEL7402/FUT8 tumor was observed, as compared with that in the BEL7402 group and the BEL7402/mock group. Within the BEL7402/ FUT4, FUT6 or FUT8 group, an increase in tumor growth was found in the group without 5 -FU, compared with that with 5 -FU ( $\left.{ }^{*} P<0.05\right)$. Upregulation of FUT4, FUT6 or FUT8 was also shown using real-time RT-PCR $(\mathbf{f})$ and IHC staining $(\mathbf{g})$ in xenograft tumors derived from BEL7402/FUT4, FUT6 or FUT8 cells $(400 \times)$. The data are means \pm S.D. of three independent assays $\left({ }^{\star} P<0.05\right)$ 
compared with the BEL7402/mock cells. MTT and MTS assays revealed that $\mathrm{IC}_{50}$ values of four drugs were higher in BEL7402/FUT4, BEL7402/FUT6 and BEL7402/FUT8 groups than those in the BEL7402/mock groups, suggesting a positive correlation between the three gene expression and chemoresistance of human HCC cells (Figure $4 d$ and Supplementary Figure 1b).

Nude mice were inoculated with tumor cells BEL7402, BEL7402/mock, BEL7402/FUT4, BEL7402/FUT6 and BEL7402/FUT8. Tumor volumes were measured and compared between the groups with or without 5-FU treatment. In the group of mice bearing BEL7402 tumor, tumor volume with 5 -FU treatment $\left(353 \pm 51 \mathrm{~mm}^{3}\right)$ was lower than those without $\left(537 \pm 72 \mathrm{~mm}^{3}\right)$. In the group of mice bearing BEL7402/ FUT4 $\left(609 \pm 68 \mathrm{~mm}^{3}\right)$, BEL7402/FUT6 $\left(639 \pm 73 \mathrm{~mm}^{3}\right)$ or BEL7402/FUT8 $\left(625 \pm 70 \mathrm{~mm}^{3}\right)$ tumors, tumor volumes were increased obviously even after 5-FU treatment, as compared with the BEL7402/mock group (351 $\pm 58 \mathrm{~mm}^{3}$ ) (Figure $4 \mathrm{~d}$ ).

High expression levels of FUT4, FUT6 and FUT8 in tumor cells of BEL7402/FUT4, BEL7402/FUT6 and BEL7402/FUT8 were also illustrated using real-time $\mathrm{PCR}$ and $\mathrm{IHC}$ staining, as shown in Figures $4 \mathrm{f}$ and $\mathrm{g}$. Moreover, the protein level of FUT4, FUT6 or FUT8 was strongly related to the expression of Ki67 (Supplementary Figure 2b). Therefore, the upregulation of the FUT4, FUT6 or FUT8 gene in BEL7402 cells led to a raised resistance to chemotherapy.

Effect of the FUT4-, FUT6- or FUT8-activated PI3K/Akt signaling pathway on the expression of MDR-associated proteins. Given that the critical role of the PI3K/Akt pathway in controlling cell MDR, we investigated whether FUT4, FUT6 or FUT8 gene activated the PI3K/Akt pathway and whether this pathway had a central role in FUT4-, FUT6- or FUT8mediated cell MDR. Western blot analysis showed that the levels of PI3 kinase $\mathrm{p} 110 \alpha$ (the catalytic subunit of PI3K) and phosphorylation Akt were decreased in BEL/FU cells treated with FUT4, FUT6 or FUT8 shRNA (Figure 5a). Concomitantly, the degrees of phosphorylation of Akt at Ser473 and Thr308 and its downstream effector NF- $\kappa$ B were decreased markedly. By contrast, there was no change in the total amount of Akt protein, demonstrating a true decrease in the phosphorylation status. Furthermore, overexpression of FUT4, FUT6 or FUT8 in BEL7402 cells significantly enhanced protein expression of PI3K110 $\alpha$, Akt Ser473, Akt Thr308 and NF- $\kappa \mathrm{B}$ as illustrated in Figure 5b. Interestingly, electrophoretic mobility shift assay (EMSA) also revealed the same tendency of NF- $\kappa \mathrm{B}$ DNA-binding complexes on stimulation with FUT4, FUT6 or FUT8 (Supplementary Figures $3 a$ and $b$ ).

To further investigate the effect of the FUT4-, FUT6- or FUT8-modulated PI3K/Akt pathway on the expression of P-gp and MRP1, BEL/FU cells growing exponentially were treated with FUT4, FUT6 or FUT8 shRNA, and the amounts of P-gp and MRP1 were measured using flow cytometric analysis. Lower relative expression levels of MRP1 to $\mathrm{Na}+/ \mathrm{K}+$ -ATPase $\alpha 1$ were detected in BEL/FU-FUT4 shRNA, BEL/ FU-FUT6 shRNA and BEL/FU-FUT8 shRNA cells compared with those in control cells (Figure 5c). Moreover, BEL7402 cells expressed higher relative levels of MRP1 with FUT4, FUT6 or FUT8 overexpression (Figure 5d). Interestingly, in this study, we showed that, in BEL7402 and BEL/FU cell lines, the relative expression of MRP1, but not of P-gp (relative

$\mathbf{a}$
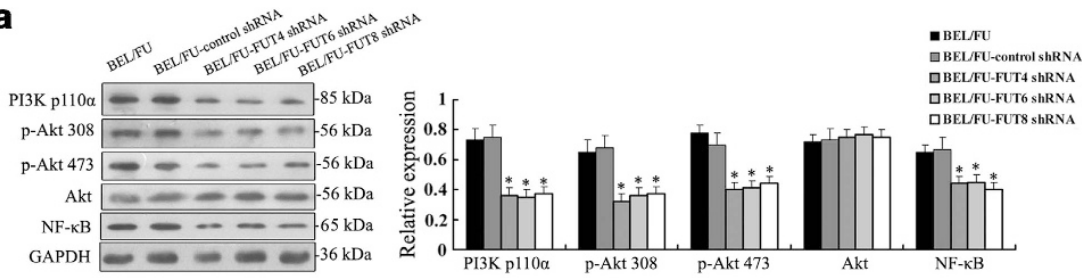

b
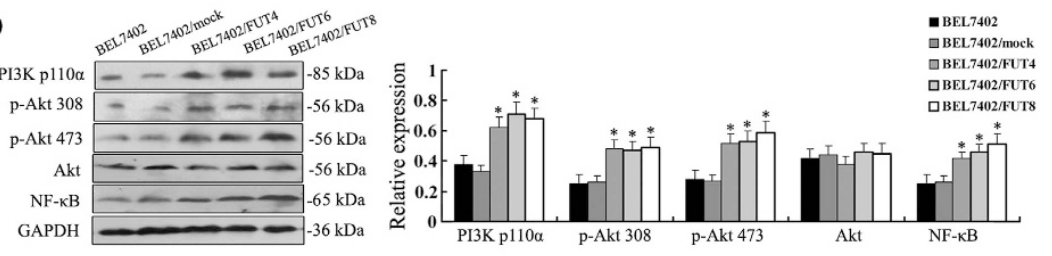

C
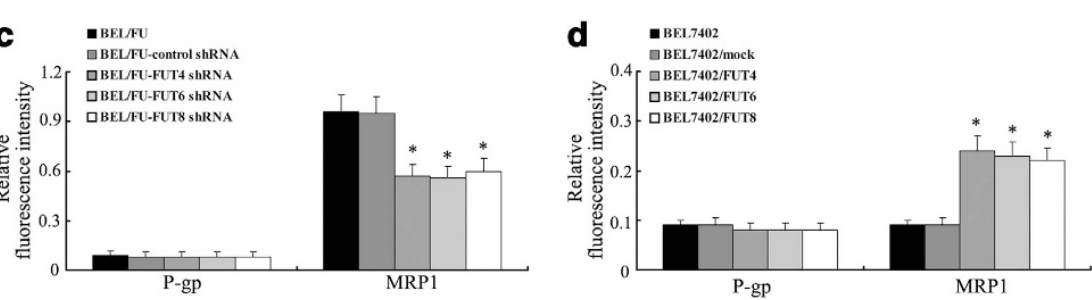

Figure 5 Effect of FUT4-, FUT6- or FUT8-activated the PI3K/Akt signaling pathway on the expression of multidrug resistance-associated proteins. (a) Expression of PI3K/ Akt/NF- $\kappa$ B signaling molecules were repressed at protein levels with FUT4, FUT6 or FUT8 shRNA transfection in BEL/FU cells. (b) The increased protein levels of PI3K/Akt/ $\mathrm{NF}-\kappa \mathrm{B}$ signaling molecules were determined using western blot in BEL7402/FUT4, FUT6 or FUT8 cells. (c) Decreased relative expression of MRP1 to Na ${ }^{+} / \mathrm{K}^{+}-\mathrm{ATPase}$ was examined using flow cytometry analysis in FUT4-, FUT6- or FUT8-shRNA-treated BEL/FU cells. (d) Flow cytometry analysis revealed a higher relative expression of MRP1 to $\mathrm{Na}^{+} / \mathrm{K}^{+}$-ATPase in BEL7402 cells with FUT4, FUT6 or FUT8 transfection. The data are means \pm S.D. of three independent assays $\left({ }^{*} P<0.05\right.$ ) 
expression to $\mathrm{Na}+/ \mathrm{K}+-\mathrm{ATPase} \alpha 1$ ), were under the control of the FUT4-, FUT6- and FUT8-modulated PI3K/Akt axis. These data together implied that FUT4, FUT6 and FUT8 might mediate the PI3K/Akt pathway with involvement of MRP1 expression.

PI3K/Akt inhibition modulates the chemosensitivity of BEL/FU cells both in vitro and in vivo. To further determine the role of FUT4-, FUT6- or FUT8-activated $\mathrm{PI} 3 \mathrm{~K} /$ Akt signaling on cell MDR, specific inhibitor of PI3K/ Akt or Akt siRNA to silence Akt was selected to treat FUT4, FUT6 and FUT8 overexpressing cells. The protein levels of PI3K110 $\alpha$, Akt Ser473, Akt Thr308, Akt and NF- $\kappa$ B were measured. As shown in Figure $6 \mathrm{a}, \mathrm{BEL} / \mathrm{FU}$ cells with the inhibitor wortmannin and Akt siRNA treatment showed significantly decreased protein levels of the main signal molecules of the PI3K/Akt pathway. EMSA assay also revealed the same tendency of NF- $\kappa$ B DNA-binding complexes on stimulation with inhibitor wortmannin and Akt siRNA treatment (Supplementary Figure 3b). Using MTT and MTS assays in vitro, we observed that inactivation of the PI3K/Akt pathway by wortmannin or silencing Akt tremendously made BEL/FU cells sensitive to chemotherapy (Figure $6 \mathrm{~b}$ and Supplementary Figure 1c); the similar results were also obtained using in vivo chemosensitivity analysis. Reduced tumor volumes were observed in the mice group bearing BEL/FU tumors with impaired PI3K/Akt signaling (Figure 6c). Altered expression levels of the main signal molecules of the PI3K/Akt pathway in the mice group bearing BEL/FU tumors with wortmannin or Akt siRNA treatment were also validated using $\mathrm{IHC}$ staining, as shown in Figure $6 \mathrm{~d}$. Moreover, the inhibitor of PI3K/Akt or silencing Akt decreased the relative expression of MRP1 to $\mathrm{Na}+/ \mathrm{K}+$ -ATPase $\alpha 1$ in BEL/FU cells, whereas the level of P-gp (relative expression to $\mathrm{Na}+/ \mathrm{K}+$-ATPase $\alpha 1$ ) was not changed (Figure 6e). These data implicated a role of PI3K/Akt
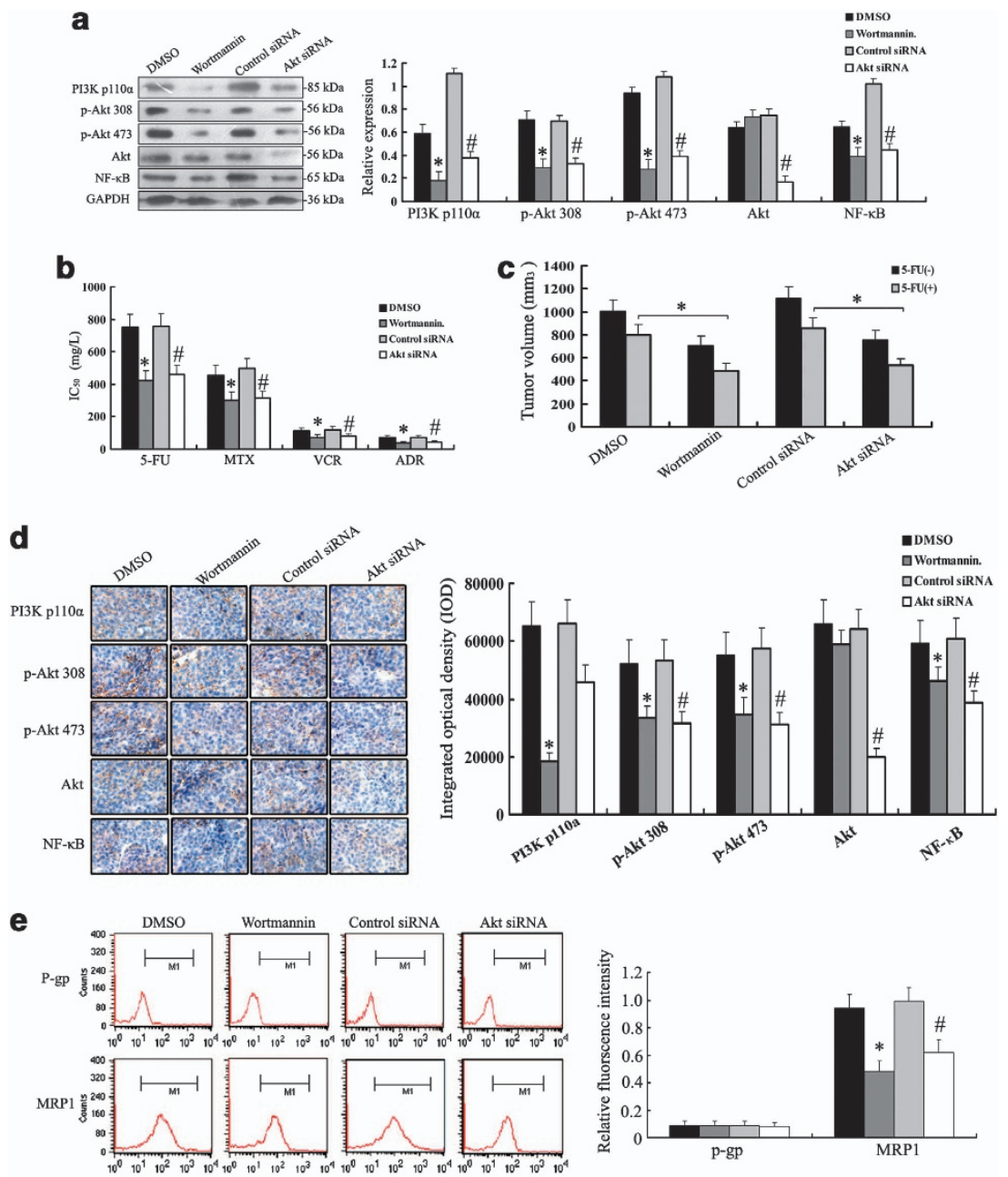

Figure $6 \mathrm{PI} 3 \mathrm{~K} / \mathrm{Akt}$ inhibition modulates the chemosensitivity of BEL/FU cells both in vitro and in vivo. (a) The BEL/FU cells were pretreated wortmannin or Akt siRNA. Expression of PI3K/Akt/NF- $\kappa$ B signaling molecules were then examined using western blot analysis. (b) Wortmannin or Akt siRNA treatment also alleviated chemoresistance of BEL/FU cells, revealed by in vitro and in vivo (c). (d) Downregulation of PI3K/Akt/NF- $\kappa$ B signaling molecules was also shown by IHC staining in xenograft tumors derived from wortmannin or Akt siRNA treatment cells $(400 \times)$. (e) Flow cytometry analysis showed that the suppression of PI3K/Akt signaling resulted in reduced-level MRP1 (relative expression to $\mathrm{Na}^{+} / \mathrm{K}^{+}$-ATPase). The data are means \pm S.D. of three independent assays. ${ }^{*} P<0.05$ versus DMSO treatment cells; ${ }^{\#} P<0.05$ vs control siRNA treatment cells 
Table 2 qRT-PCR conditions and primer sequences for analysis of gene expression

\begin{tabular}{|c|c|c|}
\hline Gene & Primers & Amplicon \\
\hline FUT1 & 5'-AAAGCGGACTGTGGATCT-3'; 5'-GGACACAGGATCGACAGG-3' & $168 \mathrm{bp}$ \\
\hline FUT2 & 5'-CTGCCCAACCACTCTGTC-3'; $5^{\prime}$-CCGTAAAGACAAAGAGGATG-3' & $117 \mathrm{bp}$ \\
\hline FUT3 & 5'-CAACAGAGAAAGCAGGCA-3'; 5'-AAGAAACACACAGCCACC-3' & $191 \mathrm{bp}$ \\
\hline FUT4 & 5'-TCCTACGGAGAGGCTCAG3'; 5'-TCCTCGTAGTCCAACACG-3' & $134 \mathrm{bp}$ \\
\hline FUT5 & 5'-ATGGCAGTGGAACCTGTC-3'; 5'-GCACCATCTCTGAGCAGC-3' & $148 \mathrm{bp}$ \\
\hline FUT6 & 5'-CATTTCTGCTGCCTCAGG-3'; 5'-GGGCAAGTCAGGCAACTC-3' & $138 \mathrm{bp}$ \\
\hline FUT7 & 5'-CCACGATCACCATCCTTG-3'; 5'-AGGCTTCGGTTGGCACTC-3' & $118 \mathrm{bp}$ \\
\hline FUT8 & 5'-TCTAGCCGAGAACTGTCC-3'; 5'-GCTGCTCTTCTAAAACGC-3' & $154 \mathrm{bp}$ \\
\hline FUT9 & 5'-CAACTGTCTACGTGCTTC-3'; 5'-AGACATGCCATGAAACAG-3' & $124 \mathrm{bp}$ \\
\hline FUT10 & 5'-ATCTTGCCTGTGCGTCAC-3'; 5'-ATGCGTAGGTGCTTCCTC-3' & $142 \mathrm{bp}$ \\
\hline FUT11 & 5'-CTCTTGGCTTTCTTGTCC-3'; 5'-ATGACGGAGTGATTGTTC-3' & $167 \mathrm{bp}$ \\
\hline GAPDH & 5'-CTCCTCCACCTTTGACGCTG-3'; 5'-TCCTCTTGTGCTCTTGCTGG-3' & $175 \mathrm{bp}$ \\
\hline
\end{tabular}

signaling in regulating MRP1 expression and modulating the chemoresistance of BEL/FU cells.

\section{Discussion}

To elucidate the mechanism of MDR, we investigated the composition of N-glycan in parental and drug-resistant human $\mathrm{HCC}$ cell lines. The fucosylated $\mathrm{N}$-glycans were dramatically increased in resistant cells. These $\mathrm{N}$-glycans were synthesized by FUTs. We further examined expression of the FUT family, which was reported to be associated with tumor MDR.

Over the past decade, extensive studies have followed the evaluation of glycan changes in proteins during disease from a variety of biological samples using different proteomic approaches, including high-sensitive MS. MS technology as a novel methodology provides high sensitivity and more rapid glycan analysis. ${ }^{29,30}$ Zhang et al. have investigated novel $\mathrm{N}$-glycan changes involved in drug resistance between leukemia cell line K562 and ADR-resistant K562/ADR using MALDI-TOF/MS. ${ }^{31}$ Moreover, differential N-glycan compositions of human breast cancer cell line MCF-7 and its ADRresistant counterpart MCF-7/ADR were identified using MS (MALDI-TOF /MS). ${ }^{32}$ In this regard, our present work was aimed to MS investigation of $\mathrm{N}$-glycans in parental and drugresistant human $\mathrm{HCC}$ cell lines. We compared the total $\mathrm{N}$-glycans from BEL7402 and BEL/FU cell lines and found dramatic differences in $\mathrm{N}$-glycan profiles between these two groups (Figure 1, Table 2). A major population of $\mathrm{N}$-glycans detected in BEL7402 and BEL/FU cells corresponded to highmannose structures (peaks 4, 8, 12, 18 and 22), and one in particular peak 4 was increased in drug-resistant BEL/FU cell line. Moreover, the major peaks (peaks 2, 5, 11, 20, 27, 29 and 31 ) that corresponded to fucosylated oligosaccharides originating from BEL/FU cells also showed a significant increase. Therefore, monitoring of the fucosylated $\mathrm{N}$-glycan profile would be an important step in the prevention of tumor MDR and would increase our understanding of resistance mechanisms.

Aberrant expression of fucosylated glycans has been detected in breast cancer, ${ }^{33} \mathrm{HCC}^{34}{ }^{34}$ colon cancer ${ }^{35}$ and lung cancer. ${ }^{36}$ The biosynthetic pathway of fucosylated glycans highlights the importance of FUTs. In this study, we also found that the expression profiles of the FUT genes were remodeled between BEL7402 and BEL/FU using a real-time PCR analysis. FUT family expressions were highly regulated, with three (out of 11) glycogenes (at least threefold, Figure 2) significantly differentially expressed among the two cell lines. Comparing with BEL7402 cells, BEL/FU cells showed a higher expression of FUT4 (3.5-folds), FUT6 (3.0-folds) and FUT8 (3.8-folds) mRNA (Figure 2a). Furthermore, two pairs of resistant and sensitive $\mathrm{HCC}$ cell lines also showed the same results, suggesting that MDR cells displayed higher $\alpha 1,3-$ and $\alpha 1,6$-linked fucosylation (core fucosylation). The major altering expression of FUTs in the three pairs of parental and chemoresistant HCC cell lines might be more important as indicators and functional contributors of tumor MDR.

Whether the alteration of MDR is caused by the change of the FUT family and its related proteins is an interesting problem. However, a comprehensive understanding of how FUT4, FUT6 and FUT8 correlate with the MDR of human HCC cells is not currently available. Here, we targeted FUT4, FUT6 and FUT8, which were differentially expressed in BEL7402 and BEL/FU cells, and altered the expression levels of three glycogenes. The altered level of FUT4, FUT6 or FUT8 was responsible for changed drug-resistant phenotypes of BEL7402 and BEL/FU cells both in vitro and in vivo (Figures 3 and 4). FUT4, FUT6 or FUT8 product also altered remarkably in HCC cell lines labeled with FITC-LTL or FITCLCA lectin (Figures $3 c$ and $4 c$ ). These results clearly showed that the change in FUT4, FUT6 or FUT8 expression level had an impact on the remodeling of cell surface fucosylated oligosaccharides, which might consequently affect the biological functions of tumor cells such as MDR resistance.

The PI3K/Akt signaling pathway controls the expression and function of many proteins that are necessary for tumor cell MDR. ${ }^{37-39}$ FUT4 regulated A431 cell growth through controlling cell cycle progression via MAPK and PI3K/Akt signaling pathways. FUT4 overexpression enhanced the DNA synthesis and increased cells in the S-phase of the cell cycle. ${ }^{40}$ FUT6 had an important role in HCC growth by regulating the PI3K/Akt signaling pathway. Elevating FUT6 expression markedly induced intracellular Akt phosphorylation and suppressed the expression of the cyclin-dependent kinase inhibitor p21.21 FUT8 was essential for EGF receptormediated biological functions via the PI3K/Akt signaling pathway. By binding to its ligand, EGFR formed homo- and heterodimers, which activated distinct downstream signaling such as the PI3K/Akt pathway. ${ }^{41,42}$ In this study, we evaluated the correlation of the FUT4-, FUT6- or FUT8-mediated PI3K/ Akt signaling pathway with MDR and the NF- $\kappa$ B pathway. 
We demonstrated that the resistant cell line BEL/FU presented higher PI3K/Akt activity than the sensitive one, which was in accordance with the MDR phenotype. Altered expression of FUT4, FUT6 or FUT8 markedly modulated the activity of the PI3K/Akt pathway in human HCC cell lines. In addition, inhibition of the PI3K/Akt pathway with Akt-specific inhibitor wortmanin, or Akt gene silencing by siRNA pretreatment, reversed chemoresistance of BEL/FU cells (Figures $6 b$ and $c$ ). These results indicated that FUT4-, FUT6- or FUT8-modulated HCC cell ADR was, at least in part, PI3K/Akt-dependent.

Increasing evidence indicates that the PI3K/Akt pathway enhances drug efflux by $A B C$ transporters, maintaining MDR of tumor cells. ${ }^{43}$ PI3K inhibitor, LY294002, has therapeutic potential when combined with doxorubicin in the treatment of MRP1-mediated drug resistance ${ }^{44}$ and is able to block P-gp efflux in mouse leukemic cell lines. ${ }^{45}$ However, a recent report in acute myelogenous leukemia has demonstrated that MRP1 but not P-gp efflux was inhibited by the PI3K inhibitor wortmannin. ${ }^{43}$ Inhibition of PI3K/Akt by LY2940002 or Akt siRNA led to the inhibition of PrPC-induced drug resistance and P-gp upregulation in gastric cancer cells. ${ }^{28}$ Here, we found that the level of MRP1 had a positive relationship with the expression of FUT4, FUT6 and FUT8 and the activity of $\mathrm{PI}$ KK/Akt in BEL7402 and BEL/FU cell lines. No significant difference of $P$-gp was found between the two cell lines, which suggested activity of $\mathrm{P}$-gp might have little role in the acquired MDR of BEL7402/5-FU. ${ }^{46}$ Consequently, the MDR mediated by the FUT family was also involved in the PI3K/Akt pathway activation and MRP1 expression.

Taken together, by analyzing the fucosylated N-glycans of BEL7402 and BEL/FU lines and detecting the quantitative changes of the FUT family, at least in this system, altered FUT4, FUT6 and FUT8 showed the unusual property of association with HCC cells' MDR via modulating the PI3K/Akt signaling pathway and MRP1 expression. Although we felt that the modification of FUT4, FUT6 and FUT8 effects remained the best explanation for the MDR phenotype, there could be other potential effects on the FUT family alteration. Therefore, the molecular bases of tumor MDR-associated phenotype remained to be further investigated.

\begin{abstract}
Materials and Methods
Cell culture. Human HCC cell lines BEL7402, HepG2 and MHCC97H were obtained from the KeyGEN Company (Nanjing, China). The cell line was cultured in $90 \%$ DMEM (Gibco, Grand Island, NY, USA) supplemented with antibiotics $(1 \times$ penicillin/streptomycin $100 \mathrm{U} / \mathrm{ml}$, Gibco) and 10\% heat-inactivated fetal bovine serum (Gibco). Cells were incubated at $37^{\circ} \mathrm{C}$ in a humidified atmosphere containing $5 \% \mathrm{CO}_{2}$. 5-FU (Sigma, St. Louis, MO, USA) was added to BEL7402, HepG2 and MHCC97H cell cultures in stepwise increasing concentrations to develop a drug-resistant cell subline BEL7402/5-FU (BEL/FU), HepG2/5-FU (HepG2/FU) and MHCC97H/5-FU (MHCC97H/FU). To maintain the MDR phenotype, the medium of the MDR cells was supplemented with $20 \mathrm{mg} / \mathrm{l} 5-\mathrm{FU}$. One week before subsequent treatments, MDR cells were maintained in complete medium without $5-\mathrm{FU}$ and cells with $>90 \%$ viability were used for further studies.
\end{abstract}

Membrane protein extract. A total of $1 \times 10^{7}$ cells were washed with phosphate-buffered saline (PBS) and lysed on a plate with lysis and separation buffer containing a protease inhibitor cocktail. Cell membrane proteins were extracted from the cell suspension using a Cellytic MEM Protein Extraction kit (Sigma). The membrane protein concentration was measured with a Micro BCA Protein Assay kit (PIERCE, Rockford, IL, USA) and used for further experiments as described below.
Release of $\mathrm{N}$-glycans from cell membrane proteins. Dried three $100 \mu \mathrm{g}$ aliquots of cell membrane proteins were first digested with trypsin $(10 \mu \mathrm{g})$ and chymotrypsin $(10 \mu \mathrm{g})$ dissolved in $25 \mathrm{mM}$ ammonium bicarbonate $(25 \mu \mathrm{l})$ at $37^{\circ} \mathrm{C}$ for $18 \mathrm{~h}$. The digest was left in a water bath $\left(85^{\circ} \mathrm{C}, 5 \mathrm{~min}\right)$, and after cooling $\mathrm{N}$-linked oligosaccharides were released from peptides by treatment with PNGaseF enzyme $(2 \mu \mathrm{l} ; 6 \mathrm{U})$ at $37^{\circ} \mathrm{C}(18 \mathrm{~h})$ followed by Pronase digestion $(10 \mu \mathrm{g})$ at $37^{\circ} \mathrm{C}(8 \mathrm{~h})$. During the incubation time, the reaction sample was mixed occasionally. The released N-glycans were purified using an Oasis HLB cartridge (60 mg per $3 \mathrm{ml}$; Waters, Milford, MA, USA) and then were lyophilized.

MS analysis. The mass spectra were acquired using an Ultraflextreme MALDITOF/TOF (Bruker Daltonics, Bremen, Germany). To increase the sensitivity and provide more informative fragmentation, the released glycans were permethylated and further characterized by MALDI-TOF MS. For the type of MALDI analysis of the permethylated glycans, 2,5-DHB was used as the matrix. Values are the mean \pm S.D. of three permethylated samples from $\mathrm{N}$-glycan samples. All MS spectra were obtained from $\mathrm{Na}+$ adduct ions.

Real-time PCR analysis. Real-time PCR was used to analyze gene expression. Total RNA was isolated using the RNeasy Mini Kit (QIAGEN, Valencia, CA, USA), and CDNA was synthesized using the QuantiTect Reverse Transcription Kit (QIAGEN) according to the manufacturer's protocol. Real-time PCR was carried out on an ABI Prism 7500 fast real-time PCR system (Applied Biosystems, Foster City, CA, USA) using QuantiTect SYBR Green PCR Kit (QIAGEN). The primer pairs for PCR are listed in Table 2. The relative expression level of each gene was normalized to that of the respective GAPDH. Relative fold differences were determined using the method of delta-delta CT.

Western blot analysis. Whole-cell proteins were electrophoresed under reducing conditions in $10 \%$ polyacrylamide gels. The separated proteins were transferred to a polyvinylidene difluoride membrane (Pall Corporation, Port Washington, NY, USA). After blocking with $5 \%$ skimmed milk in PBS containing $0.1 \%$ Tween 20 (PBST), the membrane was incubated with antibody (ABGENT, San Diego, CA, USA, 1:500 dilution; Abcam, Cambridge, UK, 1:1000 dilution) and then with peroxidase-conjugated anti-rabbit IgG (Santa Cruz Biotechnology, Santa Cruz, CA, USA, 1:1000 dilution). GAPDH (Santa Cruz Biotechnology, $1: 1000$ dilution) was used as a control. All band intensities were evaluated using ECL western blotting kit (Amersham Biosciences, Little Chalfont, UK) and were normalized to those of GAPDH.

Deregulation of FUT4, FUT6 or FUT8 in BEL/FU cells by RNAi. Transfection was performed in a 12-well plate at $\sim 50 \%$ confluent cultures. BEL/FU cells were maintained in $1 \mathrm{ml}$ of complete medium with $5 \mu \mathrm{g} / \mathrm{ml}$ Polybrene per well and were treated with $0.4 \mu \mathrm{M}$ FUT4-, FUT6- or FUT8-specific shRNA lentiviral particles overnight; three wells were transduced with control shRNA lentiviral particles. Then, the medium in each well was replaced with $1 \mathrm{ml}$ of complete medium (without Polybrene) and the cells were diluted to $1: 3$ for selecting stable clones expressing the shRNA by $5 \mu \mathrm{g} / \mathrm{ml}$ puromycin dihydrochloride. The transfection efficiency was $\sim 80 \%$ and cell viability was $90 \%$ as demonstrated the by trypan blue dye exclusion assay. Four weeks later, several resistant colonies were picked and expanded for further study.

Overexpression of FUT4, FUT6 or FUT8 in BEL7402 cells. The human FUT4, FUT6 and FUT8 coding sequences were obtained from TaKaRa company (Dalian, China) and were inserted into the pEGFP-N2 vector (Invitrogen, Carlsbad, CA, USA), respectively, using EcoRI and Xhol sites. Cells were transfected with $5 \mu \mathrm{g}$ of target gene expression vector or empty vector (EV) in 100-mm dishes using PolyFect Transfection Reagent (QIAGEN) according to the manufacturer's instruction. After 4 weeks of screening, the cell lines stably expressing FUT4 (BEL7402/FUT4), FUT6 (BEL7402/FUT6), FUT8 (BEL7402/ FUT8) and EV (BEL7402/mock) were established. Then cells were collected for gene expression assay for further explorations. The cell transfection efficiency was $78 \%$ and the survival rate was $90 \%$.

In vitro drug cytotoxic assay. Cell proliferation was measured using an MTT assay to determine the chemosensitivity of the cell groups with genetic manipulation and pharmacologic inhibition of the PI3K/Akt pathway. Cells $\left(1 \times 10^{4}\right)$ were plated in 96-well plates (Costar, Charlotte, NC, USA) and incubated with different anticancer drugs such as 5-FU (Sigma), MTX 
(Sigma), VCR (Sigma) and ADR (Sigma) for $48 \mathrm{~h}$. Then cells were treated with $100 \mu \mathrm{l}$ MTT $\left(5 \mathrm{mg} / \mathrm{ml}\right.$, Sigma). After $4-\mathrm{h}$ incubation at $37^{\circ} \mathrm{C}$ in $5 \% \mathrm{CO}_{2}, 100 \mu \mathrm{l}$ dimethyl sulfoxide (DMSO) (Gibco) was pipetted to solubilize the formazan product for $30 \mathrm{~min}$ at room temperature. Spectrometric absorbance at $490 \mathrm{~nm}$ was measured with a microplate reader. Each group contained three wells and was repeated three times. The drug resistance was estimated by comparing the $\mathrm{IC}_{50}$ values (drug concentration that inhibits cell growth by 50\%) from growth inhibition curves.

In vitro drug cytotoxic assay. The CellTiter 96 AQueous One Solution Cell Proliferation Assay (MTS) kit (Promega, Madison, WI, USA) was used to determine the chemosensitivity of cell groups with genetic manipulation and pharmacologic inhibition of the PI3K/Akt pathway. Cells $\left(1 \times 10^{4}\right)$ were seeded in a 96-well plate and incubated with 5-FU, MTX, VCR and ADR (Sigma) for $48 \mathrm{~h}$. Then cells were stained with $10 \mu \mathrm{l}$ MTS for $3 \mathrm{~h}$ at $37^{\circ} \mathrm{C}$. The absorbance was measured at $490 \mathrm{~nm}$ using microplate reader (Model 680; Bio-Rad, Hercules, CA, USA). The drug resistance was estimated by comparing the $\mathrm{IC}_{50}$ values from growth inhibition curves.

In vivo chemosensitivity assay. To investigate whether FUT4, FUT6 or FUT8 is related to drug sensitivity of tumor cell in vivo, the chemosensitivity of 5 -FU was examined in nude mice bearing tumor cell xenografts. Five-week-old male athymic nude mice were obtained from Animal Facility of Dalian Medical University and were provided with sterilized food and water. Approximately, $1 \times 10^{7}$ cells were injected subcutaneously into the right flank of each nude mouse, respectively. When mice bearing palpable tumors (about 1 week after tumor cell inoculation), BEL7402, BEL7402/mock, BEL7402/FUT4, FUT6 or FUT8, BEL/FU, BEL/FU-control shRNA BEL/FU-FUT4, FUT6 or FUT8 shRNA tumor-bearing mice were randomly divided into control and treatment groups ( $n=6$ animals per group). The treatment groups received $30 \mathrm{mg} / \mathrm{kg} 5$-FU i.p. three times per week for 3 weeks, and the control groups received physiological saline alone. Mice were killed and their tumors were isolated. The external caliper was used to determine the volume of xenografted tumors; the tumor volume was calculated by the following formula: tumor volume $=1 / 2\left(\right.$ length $\times$ width $\left.^{2}\right)$.

Inhibition of the PI3K/Akt signaling. Wortmannin (Sigma) was used to suppress the activity of the PI3K/Akt signaling in BEL/FU cells. Briefly, cells $\left(1 \times 10^{4}\right.$ cells per well) were incubated with DMSO (Sigma) or the PI3K inhibitor wortmannin $(1 \mathrm{mM})$ dissolved in DMSO. Cells were collected after $24 \mathrm{~h}$. Changes in chemosensitivity and gene expression were measured using MTT and MTS assays and western blot analysis, respectively. Each experiment was run in triplicate to determine the means and S.Ds.

Nuclear extractions and EMSA. Nuclear extracts were prepared as previously described. ${ }^{47}$ DNA-binding activity of NF- $\kappa$ B was analyzed using EMSA, and the following sequence was used as specific oligomer for $N F-\kappa B$ : 5'-AGTTGAGGGGACTTTCCCAGGC-3' (sense). Reaction mixtures (15 ml) contained, together with $10 \mathrm{mg}$ of nuclear extracts, $2 \mathrm{mg}$ of poly (dl-dC) (Sigma) and $10 \mathrm{ng}$ of biotin-labeled probes. For competition experiments, 100 -fold excess of unlabeled competitor oligos were added to the extracts before the addition of labeled probes. The supershift analysis for NF- $\kappa \mathrm{B} / \mathrm{DNA}$ complex formation was determined with the NF- $\kappa$ B p65 antibody (sc-372, Santa Cruz Biotechnology), respectively. Biotin-labeled DNA-protein complexes were detected by the streptavidin conjugated with HRP (Panomics, Redwood, CA, USA).

Flow cytometry analysis. Tumor cells were washed with $1 \times$ PBS buffer containing $20 \mathrm{~g} / \mathrm{l}$ bovine serum and then were preincubated with $5 \%$ powdered skim milk for $30 \mathrm{~min}$ to block nonspecific binding. Cells were placed in sterile conical tubes in aliquots of 500000 cells each and stained with one of the FITCLTL and FITC-LCA lectins at a final concentration of $10 \mu \mathrm{g} / \mathrm{ml}$ for 40 min at $4{ }^{\circ} \mathrm{C}$ in the dark. For surface staining of P-gp and MRP1, aliquots of cells were incubated with fluorescein isothiocyanate-anti-human P-gp, MRP1 (Abcam) or a $\mathrm{Na}^{+} / \mathrm{K}^{+}$-ATPase $\alpha 1$ control antibody (Santa Cruz Biotechnology) for $40 \mathrm{~min}$ at $4^{\circ} \mathrm{C}$ at the recommended dilutions. After repeated centrifugation at $1000 \mathrm{r} / \mathrm{min}$, labeled cells were resuspended in $0.2 \mathrm{ml}$ PBS and were analyzed with FACSCalibur (BD Biosciences, San Jose, CA, USA). Fluorescence intensity was measured using the Cell Quest software (BD Biosciences). The relative P-gp or MRP1 expression level was normalized to that of the respective $\mathrm{Na}^{+} / \mathrm{K}^{+}$. ATPase $\alpha 1$. Each experiment was run in triplicate to determine means and S.Ds.
IHC staining analysis. Visible tumors were removed from the mice and immunohistochemistry was performed on paraffin-embedded sections. The slides were dried, deparaffinized, rehydrated and then were immersed in $3 \%$ hydrogen peroxide for $10 \mathrm{~min}$ to quench the endogenous peroxidase. After consecutive washing with PBS, the slides were labeled overnight at $4{ }^{\circ} \mathrm{C}$ with FUT4, FUT6 and FUT8 antibodies (ABGENT, 1:50 dilution), or Ki67 antibody (sc-15402, Santa Cruz Biotechnology, 1:50 dilution), or isotype immunoglobulins (Santa Cruz Biotechnology) as negative control. The following staining was performed at room temperature for $60 \mathrm{~min}$ with secondary streptavidin-HRP-conjugated antibody (Santa Cruz Biotechnology). Finally, the sections were counterstained with hematoxylin and coverslipped. The Image-Pro Plus 4.5 Software (Media Cybernetics, Bethesda, MD, USA) was used to analyze the expression of proteins.

Statistical analysis. Each experiment was performed at least in triplicate, and the measurements were performed in three independent experiments. Data are expressed as means \pm S.D. Student's $t$-test was used to compare the means of two groups. $P<0.05$ was considered statistically significant. All analyses were performed using SPSS 13.0 statistical packages (SPSS Inc., Chicago, IL, USA).

\section{Conflict of Interest}

The authors declare no conflict of interest.

Acknowledgements. This work was supported by grants from the National Key Basic Research and Development Program (973 program) of China (no. 2012CB822100), National Natural Science Foundation of China (81071415, 81271910) and from the Natural Science Foundation of Liaoning Province, China (20102052).

1. Tong SW, Yang YX, Hu HD, An X, Ye F, Hu P et al. Proteomic investigation of 5 -fluorouracil resistance in a human hepatocellular carcinoma cell line. J Cell Biochem 2012; 113: 1671-1680.

2. Szakács G, Paterson J. Targeting multidrug resistance in cancer. Nat Rev Drug Discover 2006; 5: 219-234.

3. Teodori E, Dei S, Martelli C, Scapecchi S, Gualtieri F. The functions and structure of ABC transporters: implications for the design of new inhib-itors of Pgp and MRP1 to control multidrug resistance (MDR). Curr Drug Targets 2006; 7: 893-909.

4. Baguley BC. Multidrug resistance in cancer. Methods Mol Biol 2010; 596: 1-14.

5. Uchibori K, Kasamatsu A, Sunaga M, Yokota S, Sakurada T, Kobayashi E et al. Establishment and characterization of two 5 -fluorouracil-resistant hepatocellular carcinoma cell lines. Int J Oncol 2012; 40: 1005-1010.

6. Lou B, Fan J, Wang K, Chen W, Zhou X, Zhang J et al. N1-guanyl-1,7-diaminoheptane (GC7) enhances the therapeutic efficacy of doxorubicin by inhibiting activation of eukaryotic translation initiation factor 5A2 (elF5A2) and preventing the epithelialmesenchymal transition in hepatocellular carcinoma cells. Exp Cell Res 2013; S00144827: 00339-0033.

7. Kudo T, Nakagawa H, Takahashi M, Hamaguchi J, Kamiyama N, Yokoo H. N-glycan alterations are associated with drug resistance in human hepatocellular carcinoma. Mol Cancer 2007; 6: 32-40.

8. Guo R, Cheng L, Zhao Y, Zhang J, Liu C, Zhou H et al. Glycogenes mediate the invasive properties and chemosensitivity of human hepatocarcinoma cells. Int J Biochem Cell Biol 2013; 45: 347-358

9. Brockhausen I. Mucin-type O-glycans in human colon and breast cancer: glycodynamics and functions. EMBO Rep 2006; 7: 599-604.

10. Ma B, Simala-Grant JL, Taylor DE. Fucosylation in prokaryotes and eukaryotes. Glycobiology 2006; 16: 158-184.

11. De VT, Knegtel RM, Holmes EH, Macher BA. Fucosyltransferases: structure/function studies. Glycobiology 2001; 11: 119-128.

12. Chandrasekaran EV, Jain RK, Rhodes JM, Srnka CA, Larsen RD, Matta KL. Expression of blood group. Lewis b determinant from Lewis a: association of this novel alpha (1, 2)-L-fucosylating activity with the Lewis type alpha (1, 3/4)-L-fucosyltransferase. Biochemistry 1995; 34: 4748-4756.

13. Roseman S. Reflections on glycobiology. J Biol Chem 2001; 276: 41527-41542.

14. Liu YC, Yen HY, Chen CY. Sialylation and fucosylation of epidermal growth factor receptor suppress its dimerization and activation in lung cancer cells. Proc Natl Acad Sci USA 2011; 108: 11332-11337.

15. Iwamori M, Tanaka K, Kubushiro K. Alterations in the glycolipid composition and cellular properties of ovarian carcinoma-derived RMG- 1 cells on transfection of the $\alpha 1$, 2-fucosyltransferase gene. Cancer Sci 2005; 96: 26-30.

16. Zhao $Y$, Lin B, Hao YY. The effects of Lewis(y) antigen content on drug resistance to carboplatin in ovarian cancer line RMG-I. Prog Biochem Biophys 2008; 35: 1175-1182. 
17. Yang X, Zhang Z, Jia S, Liu Y, Wang X, Yan Q. Overexpression of fucosyltransferase IV in A431 cell line increases cell proliferation. Int J Biochem Cell Biol 2007; 39 1722-1730.

18. Wang QY, Guo P, Duan LL, Shen ZH, Chen HL. alpha-1, 3-Fucosyltransferase-VII stimulates the growth of hepatocarcinoma cells via the cyclin-dependent kinase inhibitor p27Kip1. Cell Mol Life Sci 2005; 62: 171-178.

19. Hiller KM, Mayben JP, Bendt KM, Manousos GA, Senqer K, Cameron HS et al. Transfection of alpha $(1,3)$ fucosyltransferase antisense sequences impairs the proliferative and tumorigenic ability of human colon carcinoma cells. Mol Carcinog 2000; 27: 280-288.

20. Borsig L, Imbach T, Hochli M, Berger EG. a1, 3-Fucosyltransferase VI is expressed in HepG2 cells and codistributed with a1, 4-galactosyltransferase I in the Golgi apparatus and monensin-induced swollen vesicles. Glycobiology 1999; 9: 1273-1280.

21. Guo Q, Guo B, Wang Y, Wu J, Jiang W, Zhao $S$ et al. Functional analysis of a1, 3/4-fucosyltransferase VI in human hepatocellular carcinoma cells.. Biochem Biophys Res Commun 2012; 417: 311-317.

22. Wang $\mathrm{H}$, Wang $\mathrm{QY}$, Zhang $\mathrm{Y}$, Shen $\mathrm{ZH}$, Chen HL. Alpha1, 3 Fucosyltransferase-VII modifies the susceptibility of apoptosis induced by ultraviolet and retinoic acid in human hepatocarcinoma cells. Glycoconj J 2007; 24: 207-220.

23. Kang X, Wang N, Pei C, Sun L, Sun R, Chen J et al. Glycan-related gene expression signatures in human metastatic hepatocellular carcinoma cells. Exp Ther Med 2012; 3 : 415-422.

24. Katso R, Okkenhaug K, Ahmadi K, White S, Timms J, Waterfield MD. Cellular function of phosphoinositide 3-kinases: implications for development, homeostasis, and cancer Ann Rev Cell Dev Biol 2001; 7: 615-675.

25. Bellacosa A, Kumar CC, Di Cristofano A, Testa JR. Activation of AKT kinases in cancer: implications for therapeutic targeting. Adv Cancer Res 2005; 94: 29-86.

26. Morishita N, Tsukahara H, Chayama K, Ishida T, Washio K, Miyamura T et al. Activation of Akt is associated with poor prognosis and chemotherapeutic resistance in pediatric B-precursor acute lymphoblastic leukemia. Pediatr Blood Cancer 2012; 59 : 83-89.

27. Liu F, Liu S, He S, Xie Z, Zu X, Jiang Y. Survivin transcription is associated with P-glycoprotein/MDR1 overexpression in the multidrug resistance of MCF-7 breast cance cells. Oncol Rep 2010; 23: 1469-1475.

28. Liang J, Ge F, Guo C, Luo G, Wang X, Han G et al. Inhibition of PI3K/Akt partially leads to the inhibition of $\operatorname{PrP}(C)$-induced drug resistance in gastric cancer cells. FEBS J 2009; 276 685-694.

29. Dell A, Morris HR. Glycoprotein structure determination by mass spectrometry. Science 2001; 291: 2351-2356.

30. Harvey DJ. Proteomic analysis of glycosylation: structural determination of $\mathrm{N}$-and O-linked glycans by mass spectrometry. Expert Rev Proteomics 2005; 2: 87-101.

31. Zhang $\mathrm{MH}, \mathrm{Xu} X \mathrm{XH}$, Wang $\mathrm{Y}$, Ling $\mathrm{QX}, \mathrm{Bi} \mathrm{YT}$, Miao XJ et al. A prognostic biomarker for gastric cancer with lymph node metastases. Anat Rec (Hoboken) 2013; 296 590-594.

32. Ma H, Miao X, Ma Q, Zheng W, Zhou H, Jia L. Functional roles of glycogene and $\mathrm{N}$-glycan in multidrug resistance of human breast cancer cells. IUBMB Life 2013; 65 409-422.

33. Lattová E, Tomanek B, Bartusik D, Perreault H. N-glycomic changes in human breast carcinoma MCF-7 and T-lymphoblastoid cells after treatment with herceptin and herceptin/ Lipoplex. J Proteome Res 2010; 9: 1533-1540.
34. Shu H, Zhang S, Kang X, Li S, Qin X, Sun C et al. Protein expression and fucosylated glycans of the serum haptoglobin-\{beta\} subunit in hepatitis $B$ virus-based liver diseases. Acta Biochim Biophys Sin (Shanghai) 2011; 43: 528-534.

35. Mejías-Luque R, López-Ferrer A, Garrido M, Fabra A, de Bolós C. Changes in the invasive and metastatic capacities of $\mathrm{HT}-29 / \mathrm{M} 3$ cells induced by the expression of fucosyltransferase 1. Cancer Sci 2007; 98: 1000-1005.

36. Vasseur JA, Goetz JA, Alley WR, Novotny MV. Smoking and lung cancer-induced changes in N-glycosylation of blood serum proteins. Glycobiology 2012; 22: 1684-1708.

37. Lin X, Zhang $X$, Wang $Q$, Li J, Zhang $P$, Zhao $M$ et al. Perifosine downregulates MDR1 gene expression and reverses multidrug-resistant phenotype by inhibiting PI3K/Akt/NF- $\kappa B$ signaling pathway in a human breast cancer cell line. Neoplasma 2012; 59: 248-256.

38. Li L, Wei XH, Pan YP, Li HC, Yang H, He QH et al. LAPTM4B: a novel cancer-associated gene motivates multidrug resistance through efflux and activatingPI3K/AKT signaling. Oncogene 2010; 29: 5785-5795

39. Bao R, Lai CJ, Wang DG, Qu H, Yin L, Zifcak B et al. Targeting heat shock protein 90 with CUDC-305 overcomes erlotinib resistance in non-small cell lung cancer. Mol Cancer Ther 2009; 8: 3296-3306.

40. Yang XS, Liu S, Liu YJ, Liu JW, Liu TJ, Wang XQ et al. Overexpression of fucosyltransferase IV promotes A431 cell proliferation through activating MAPK and PI3K/ Akt signaling pathways. J Cell Physiol 2010; 225: 612-619.

41. Takahashi M, Yokoe S, Asahi M, Lee SH, Li W, Osumi D et al. N-glycan of ErbB family plays a crucial role in dimmer formation and tumor promotin. Biochim Biophys Acta 2008; 1780: $520-524$.

42. Wang $\mathrm{X}, \mathrm{Gu} \mathrm{J}$, Ihara $\mathrm{H}$, Miyoshi $\mathrm{E}$, Honke $\mathrm{K}$, Tangiguchi N. Core fucosylation regulates epidermal growth factor receptor-mediated intracellular signal. J Biol Chem 2006; 281 2572-2577.

43. Tazzari PL, Cappellini A, Ricci F, Evangelisti C, Papa V, Grafone T et al. Multidrug resistance-associated protein 1 expression is under the control of the phosphoinositide 3 kinase/Akt signal transduction network in human acute myelogenous leukemia blasts. Leukemia 2007; 21: 427-438.

44. Abdul-Ghani R, Serra V, Györffy B, Jürchott K, Solf A, Dietel M et al. The PI3K inhibitor LY294002 blocks drug export from resistant colon carcinoma cells overexpressing MRP1. Oncogene 2006; 25: 1743-1752.

45. Barancík M, Bohácová V, Sedlák J, Sulová Z, Breier A. LY294002, a specific inhibitor of $\mathrm{PI} 3 \mathrm{~K} /$ Akt kinase pathway, antagonizes P-glycoprotein-mediated multidrug resistance. Eur J Pharm Sci 2006; 29: 426-434.

46. Gu W, Fang FF, Li B, Cheng BB, Ling CQ. Characterization and resistance mechanisms of a 5-fluorouracil-resistant hepatocellular carcinoma cell line. Asian Pac J Cancer Prev 2012; 13: $4807-4814$.

47. Kasperczyk H, La Ferla-Bruhl K, Westhoff MA, Behrend L, Zwacka RM, Debatin K-M et al. Betulinic acid as new activator of NF-kappaB: molecular mechanisms and implications for cancer therapy. Oncogene 2005; 24: 6945-6956.

(c) (i) $\odot$ Cell Death and Disease is an open-access journa published by Nature Publishing Group. This work is licensed under a Creative Commons Attribution-NonCommercialNoDerivs 3.0 Unported License. To view a copy of this license, visit http://creativecommons.org/licenses/by-nc-nd/3.0/

\section{Supplementary Information accompanies this paper on Cell Death and Disease website (http://www.nature.com/cddis)}

